\title{
Numerical Simulation of Primary Roof Collapse in Production Workings
}

\author{
Inna Ermakova ${ }^{1 *}$, Viktor Klimov ${ }^{2}$ \\ ${ }^{1}$ T. F. Gorbachev Kuzbass State Technical University, 650000, Vesennaya st., 28, Kemerovo, Russia \\ ${ }^{2}$ JSC "SUEK-Kuzbass", 652507, Russia, Leninsk-Kuznetskiy, Vasilieva street, 1.
}

\begin{abstract}
The study presents the formulation of the problem that is a numerical calculation of stress-strain state of the rock mass in the vicinity of the production working by the finite element method. The estimated area had a rectangular shape and included the coal seam, the roof and soil strata, and the production working. All the blocks of the estimated area being in the state of plain strain were taken as linearly deformable. The area of roof rock destruction was established by Mohr criterion. The analytical dependence of the height of primary roof strata collapse on the roof strata ultimate compression strength, the depth and the length of the mined area has been obtained. This result allows us to estimate the initial step of roof collapse.
\end{abstract}

\section{Introduction}

The estimation of the initial step of roof caving is one of the main tasks of rock mechanics during coal-face operations. Many studies were devoted to this issue using various approaches to the task formulation and methods of solution [1-7]. This paper uses the method of finite element numerical simulation of the stress-strain state of the rock strata in the vicinity of a coal face [8]. This approach is implemented in solving various problems of rock mechanics in underground mining of coal seams [9-15]. In this study, an assessment of the strength condition of the roof rocks strata is made, which made it possible to calculate the height of the primary roof collapse area.

\section{Materials and methods}

The object of the study is roof strata of production faces with different strength characteristics.

To address the issue of the primary roof strata caving, it is required to conduct analysis of their stress-strain and strength state and to set the dimensions of the disturbed areas. The finite element method was used to calculate the stress-strain state of the roof rock. The area of roof rock collapse was established by Mohr criterion.

\footnotetext{
* Corresponding author: eia.pm@kuzstu.ru
} 


\section{Results and discussions}

We considered the stress-strain state of the rocks in the first period of coal-face operations before the collapse of roof rocks. The estimated rectangular area included the following blocks: coal seam 1; goaf 2; enclosing roof strata and seam floor strata 3 (Fig. 1). The boundary conditions and loads were taken in the following form. At the upper boundary of the computation area $\mathrm{AB}$ there is no load (daylight area). At the lower boundary $\mathrm{CD}$ remote from the pillar, there are no normal displacements (the border is fixed). The vertical boundaries $\mathrm{BC}$ and $\mathrm{AD}$, quite remote from the mined-out area, are not influenced by the coal face and have no horizontal movements.

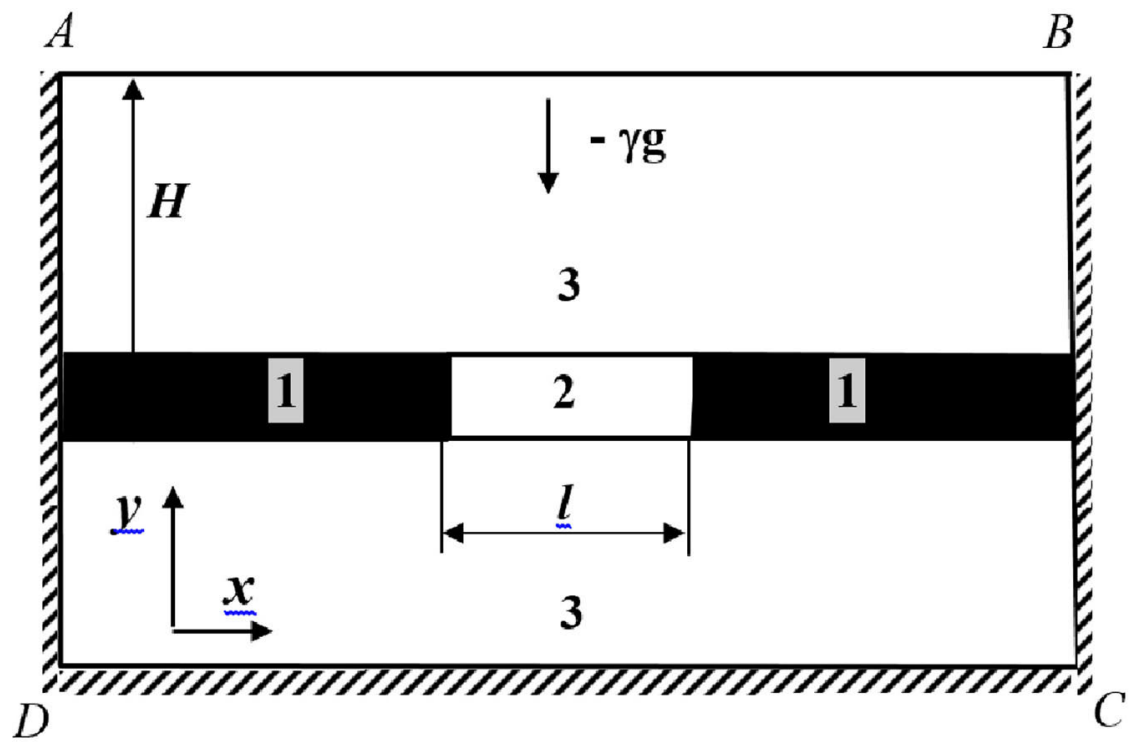

Fig. 1. The estimated area: 1 - mined-out area; 2 - coal seam; 3 - enclosing rock strata

The coal seam is loaded with body force $-\gamma=14000 \mathrm{~N} / \mathrm{m}^{3}, \mathrm{E}=10^{9} \mathrm{~N} / \mathrm{m}^{2}, v=0,25$.

The roof rock strata is loaded with the body force $-\gamma=25000 \mathrm{~N} / \mathrm{m}^{3}$ which corresponds to the weight of the enclosing strata; Young modulus $E=10^{10} \mathrm{~N} / \mathrm{m}^{2}$, Poisson ratio $v=0,25$.

The floor strata is also loaded with the body force $-\gamma=25000 \mathrm{~N} / \mathrm{m}^{3}$ corresponding to the weight of the enclosing strata: Young modulus $E=4 \cdot 10^{9} \mathrm{~N} / \mathrm{m}^{2}$, Poisson ratio $v=0,25$.

The limits of the enclosing strata compressive strength ranged from 20 to $60 \mathrm{MPa}$, and ratio of rock tensile strength limits to compressive strength was $1: 10$. The length of the production face ranged from 20 to $50 \mathrm{~m}$, the depth of mining varied from 200 to $500 \mathrm{~m}$, and the seam thickness -from 2 to $5 \mathrm{~m}$. Total 80 numerical experiments were carried out. The stress-strain state of the computational area was described by linear deformable blocks behavior. All the blocks were loaded by their own weight. The problem is solved by finite element method (FEM) using the licensed program ELCUT.

Fig. 2 shows the distribution of vertical and horizontal stresses exceeding their initial value, i.e. high rock pressure zone (light background) and pressure release zone (dark background).

The distribution of increased and decreased stresses agrees in quality with the available views on the situation of the pressure release zones in the blocks of roof and floor rock strata during coal-face operations. 
a)

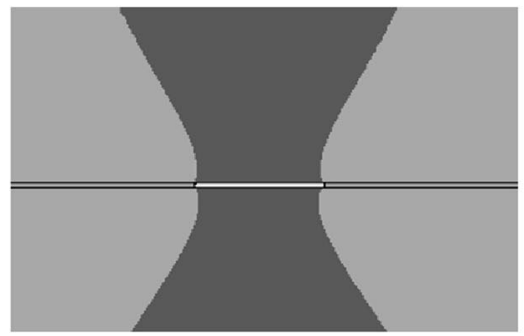

b)

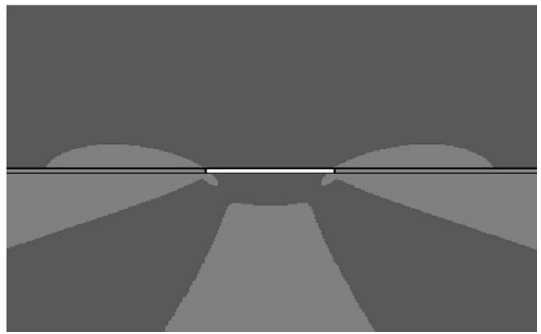

Figure 2. Distribution of increased and decreased vertical (a) and horizontal (b) stresses in the vicinity of the mine working

To assess the strength (cavability) of roof rock, the strength criterion of Mohr-Coulomb was used that was assigned in the form of principal stresses and ultimate strength as follows:

$$
\sigma_{1}-\frac{\sigma_{t}}{\sigma_{s}} \cdot \sigma_{2}<\sigma_{t},
$$

where $\sigma_{1}$ and $\sigma_{2}-$ the highest and the lowest principal stress; $\sigma_{\mathrm{s}}, \sigma_{\mathrm{t}}-$ rock strength and tensile limits.

The strength parameters are expressed via the angle of internal friction $\phi$ and engagement $k$ as follows

$$
\sigma_{s}=2 k \cos \phi /(1-\sin \phi) ; \sigma_{t}=2 k \cos \phi /(1+\sin \phi),
$$

where $k$ - engagement; $\phi$ - angle of internal friction.

Fig. 3 shows the example of calculation of the roof caving zones above the mined-out areas having seam thickness $3 \mathrm{~m}$, depth of mining $500 \mathrm{~m}$, length of production face $50 \mathrm{~m}$. At limit rock compression strength $\sigma_{\mathrm{s}}=60 \mathrm{MPa}$ roof collapses in the area where $\sigma_{\mathrm{MO}}>6$ $\mathrm{MPa}$ (dark contour). In case $\sigma_{\mathrm{s}}=20 \mathrm{MPa}$, roof collapses in the area where $\sigma_{\mathrm{MO}}>2 \mathrm{MPa}$ (the lightest contour).

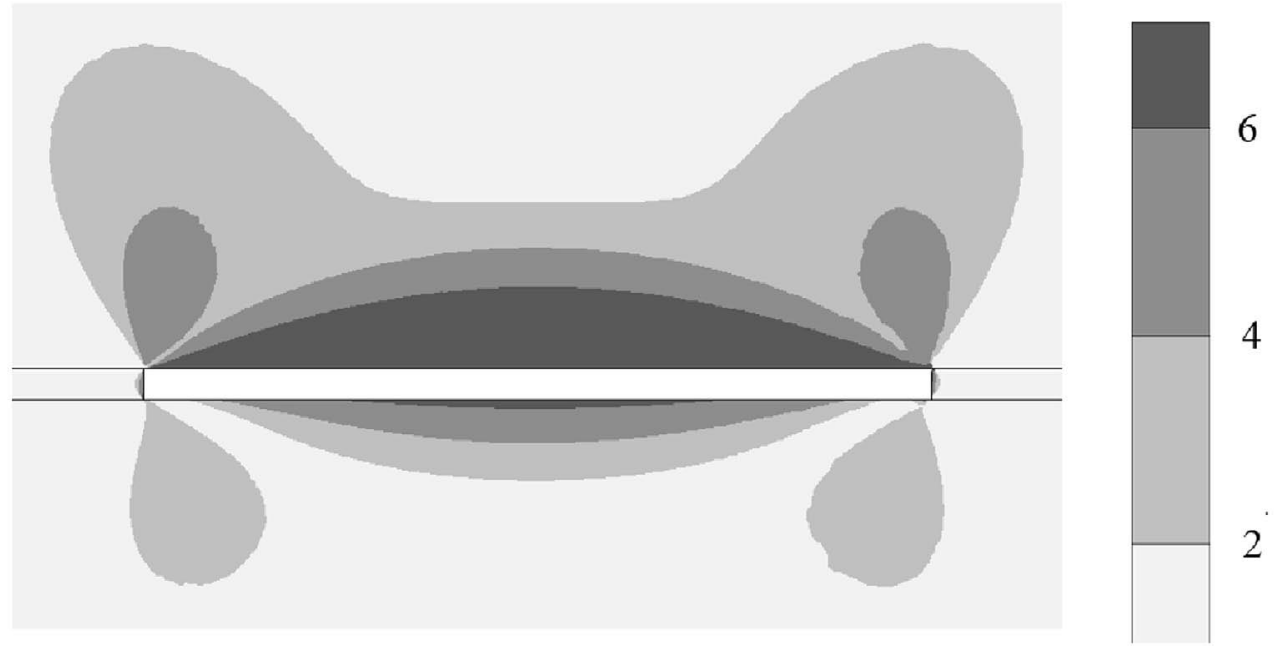

Figure 3. Areas of roof strata collapse in the seam $3 \mathrm{~m}$ thick at the mining depth $500 \mathrm{~m}$ and production face length $50 \mathrm{~m}$ 
The area of roof strata collapse was characterized by height (thickness) of this area at the level of the middle of the mine working. The performed numerical experiments have established the dependence of the change in the height of the collapsed area on the parameters of the problem. In accordance with the theory of similarity the sought dependence was taken in the following form:

$$
\frac{h}{l}=F\left(\frac{m}{l} ; \frac{\sigma_{t}}{\gamma H}\right),
$$

where $h$ - thickness of collapsed rock; $l$ - length of the production face; $m$ - seam thickness; $H$-depth of mining operations; $\sigma_{t}, \gamma$ - limit tensile strength and the bulk weight of roof strata respectively.

The statistical processing of the results of numerical experiments revealed the following. The dependence of the height of collapsed rock on the seam thickness is not significant within the considered seam thickness 2 to $5 \mathrm{~m}$. This circumstance is due to the fact that the reviewed formulation of the problem does not take into account the scale factor, i.e. the dependence of coal deformation and strength characteristics on the coal seam thickness. The rest of the problem parameters are significant and determine the dependence of the relative height of the collapse on the considered parameters as shown in Fig. 4.

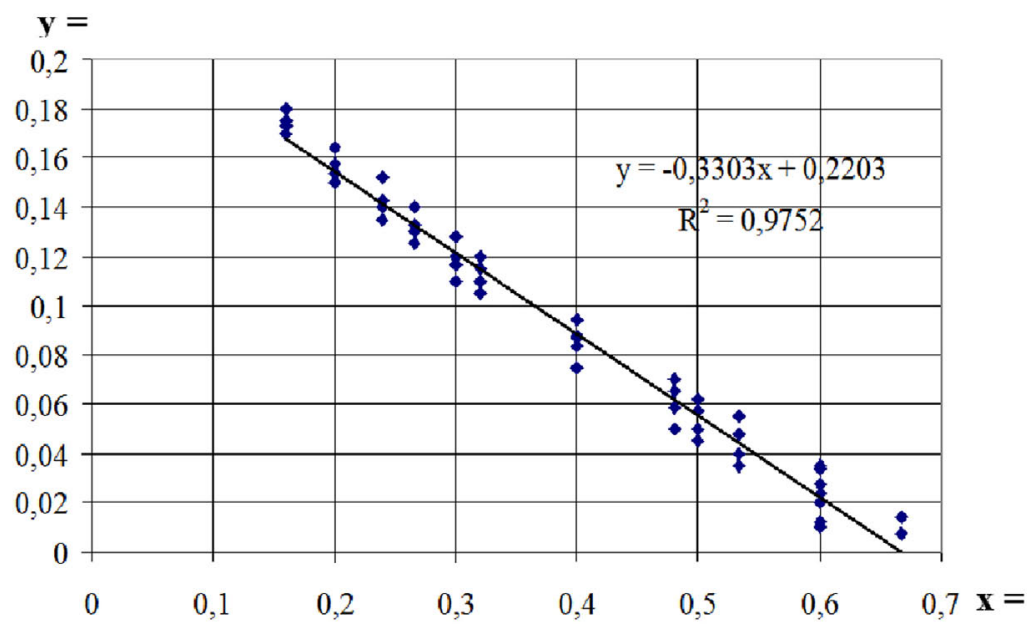

Figure 4. Results of numerical experiments and regression dependence of the relative height of roof collapse on the parameters of the problem

The regression equation allows us to express the absolute height of the roof collapse with reference to the rock tensile strength, depth and length of the production face in the following formula:

$$
h=\left(-0,3303 \cdot \sigma_{t} / \gamma H+0,2203\right) \cdot l .
$$

In the resulting formula, the rock tensile strength can be replaced by hardness ratio, as at the ratio $\sigma_{t} / \sigma_{p}=1: 10$ the numerical value of tensile strength coincides with the hardness ratio.

The resulting expression for the height of collapsed rock can also be used to determine the initial step of roof caving, which in this case is equal to the length of the production face. 


\section{Conclusions}

1. The numerical simulation of the strength state and the roof rock collapse at the initial stage of coal-face operations was made on the basis of the finite element method.

2. The dependence of the height of the initially caved roof layer on the length of the production face, roof strata strength and mining depth of coal seam was obtained.

3. It is proposed to use the suggested method of estimation of roof strata rock mechanics at the initial stage of longwall mining in the mines of JSC "SUEK-Kuzbass".

The authors express their gratitude to JSC "SUEK-Kuzbass" for the financial support of the given study.

\section{References}

1. Bieniawski Z. T., Int. J.Rock Mech. Min. Sci., 6, 323 (1969)

2. Bieniawski Z., Mir, 254 (1990)

3. Zienkiewicz, O.C.; Taylor, R.L.; Zhu, J.Z. The Finite Element Method: Its Basis and Fundamentals (7th Edition), (Butterworth-Heinemann, 2013)

4. B.H.G. Brady, E.T. Brown, Rock Mechanics for underground mining (Springer science, 2005)

5. J. Jaeger, N.G. Cook, R. Zimmerman, Fundamentals of rock mechanics (Wiley Blackwell, 2007)

6. M. Pastor, C. Tamaonini, Numerical modeling in geomechanics (Kogan Page science, 2004)

7. J.A. Hudson, J.P. Harrison, Engineering rock mechanics. An introduction to the principles (Pergamon press, 2000)

8. O. Fusao, Computer methods and recent advances in geomechanics (CRC Press, 2014)

9. M. Fremond, F. Maceri, Mechanical modeling and computational issues in civil engineering (Springer, 2005)

10. V.A. Gogolin, Y.A. Ryzhkov, Soviet Mining Science, 13, 17 (1977)

11. V.M. Seryakov, J. Min. Sci., 45, 420 (2009)

12. M.V. Kurlenya, V.E. Mirenkov, V.A. Shutov, J. Min. Sci. 50, 1001 (2014)

13. V.A. Gogolin, Y.A. Ryzhkov, Soviet Mining Science 17, 156 (1981)

14. Y.A. Ryzhkov, Y.V. Lesin, V.A. Gogolin, N.V. Karpenko, J. Min. Sci. 32, 188 (1996) 